\title{
Complete Chloroplast Genome Sequence of Aquilaria sinensis (Lour.) Gilg and Evolution Analysis within the Malvales Order
}

\author{
Ying Wang ${ }^{1}$, Di-Feng Zhan ${ }^{2}$, Xian Jia ${ }^{3}$, Wen-Li Mei ${ }^{1}$, Hao-Fu Dai ${ }^{1}$, Xiong-Ting Chen ${ }^{1 *}$ and \\ Shi-Qing Peng ${ }^{1 *}$ \\ ${ }^{1}$ Key Laboratory of Biology and Genetic Resources of Tropical Crops, Ministry of Agriculture, Institute of Tropical Bioscience \\ and Biotechnology, Chinese Academy of Tropical Agricultural Sciences, Haikou, China, ${ }^{2}$ College of Agronomy, Hainan \\ University, Haikou, China, ${ }^{3}$ State Key Laboratory of Cellular Stress Biology, School of Life Sciences, Xiamen University, \\ Xiamen, China
}

\section{OPEN ACCESS}

Edited by:

Daniel Pinero,

Universidad Nacional Autónoma de

México, México

Reviewed by:

Mehboob-ur-Rahman, National Institute for Biotechnology \& Genetic Engineering, Pakistan Shichen Wang,

Kansas State University, USA

*Correspondence:

Xiong-Ting Chen chenxiongting@itbb.org.cn; Shi-Qing Peng

pengshiqing@itbb.org.cn

Specialty section:

This article was submitted to Plant Genetics and Genomics,

a section of the journal

Frontiers in Plant Science

Received: 03 November 2015

Accepted: 21 February 2016

Published: 08 March 2016

Citation:

Wang Y, Zhan D-F, Jia X, Mei W-L,

Dai H-F, Chen X-T and Peng S-Q (2016) Complete Chloroplast Genome Sequence of Aquilaria sinensis (Lour.) Gilg and Evolution Analysis within the Malvales Order.

Front. Plant Sci. 7:280

doi: 10.3389/fpls.2016.00280
Aquilaria sinensis (Lour.) Gilg is an important medicinal woody plant producing agarwood, which is widely used in traditional Chinese medicine. High-throughput sequencing of chloroplast (cp) genomes enhanced the understanding about evolutionary relationships within plant families. In this study, we determined the complete $\mathrm{cp}$ genome sequences for $A$. sinensis. The size of the $A$. sinensis cp genome was $159,565 \mathrm{bp}$. This genome included a large single-copy region of 87,482 bp, a small single-copy region of 19,857 bp, and a pair of inverted repeats (IRa and IRb) of 26,113 bp each. The GC content of the genome was $37.11 \%$. The $A$. sinensis cp genome encoded 113 functional genes, including 82 protein-coding genes, 27 tRNA genes, and 4 rRNA genes. Seven genes were duplicated in the protein-coding genes, whereas 11 genes were duplicated in the RNA genes. A total of 45 polymorphic simple-sequence repeat loci and 60 pairs of large repeats were identified. Most simple-sequence repeats were located in the noncoding sections of the large single-copy/small single-copy region and exhibited high $\mathrm{A} / \mathrm{T}$ content. Moreover, 33 pairs of large repeat sequences were located in the proteincoding genes, whereas 27 pairs were located in the intergenic regions. Aquilaria sinensis cp genome bias ended with $\mathrm{A} / \mathrm{T}$ on the basis of codon usage. The distribution of codon usage in $A$. sinensis cp genome was most similar to that in the Gonystylus bancanus $\mathrm{cp}$ genome. Comparative results of 82 protein-coding genes from 29 species of $\mathrm{cp}$ genomes demonstrated that $A$. sinensis was a sister species to $G$. bancanus within the Malvales order. Aquilaria sinensis cp genome presented the highest sequence similarity of $>90 \%$ with the $G$. bancanus cp genome by using CGView Comparison Tool. This finding strongly supports the placement of $A$. sinensis as a sister to $G$. bancanus within the Malvales order. The complete $A$. sinensis cp genome information will be highly beneficial for further studies on this traditional medicinal plant. Moreover, the results will enhance our understanding about the evolution of $\mathrm{cp}$ genomes of the Malvales order, particularly with regard to the role of $A$. sinensis in plant systematics and evolution.

Keywords: Aquilaria sinensis (lour.) gilg, chloroplast genome, simple-sequence repeat, relative synonymous codon usage, phylogenetic analysis 


\section{INTRODUCTION}

Plant chloroplasts (cps) are key organelles for photosynthesis and carbon fixation (Neuhaus and Emes, 2000). The cp genome sequence contains useful information in plant systematics because of its maternal inheritance in most angiosperms (Corriveau and Coleman, 1988; Zhang et al., 2003). Substitution rates in plant $\mathrm{cp}$ genomes are much lower than those in nuclear genomes (Wolfe et al., 1987). Plant cp genomes are valuable sources of genetic markers for phylogenetic analyses because of their very low level of recombination (Provan et al., 2001; Ravi et al., 2008). The cp DNA sequence was initially discovered during physical mapping of the Zea mays cp, which was produced by digestion with multiple restriction enzymes (Bedbrook and Bogorad, 1976). Subsequently, the first complete nucleotide sequence of Nicotiana tabacum was determined by the clone sequencing of plasmid and cosmid libraries (Kumano, 1986). Over 600 plant cp genomes have been sequenced and deposited in the NCBI Organelle Genome Resources. The cp genome evolution in land plants may be elucidated using these database resources. The $\mathrm{cp}$ in angiosperms exhibits a conserved quadripartite structure ranging from 115 to $165 \mathrm{~kb}$ in length and consists of one large single-copy (LSC) region, one small singlecopy (SSC) region, and two copies of inverted repeat (IR; Palmer, 1991; Raubeson and Jansen, 2005). The Arabidopsis thaliana cp genome contains a circular DNA composed of 154,478 bp with

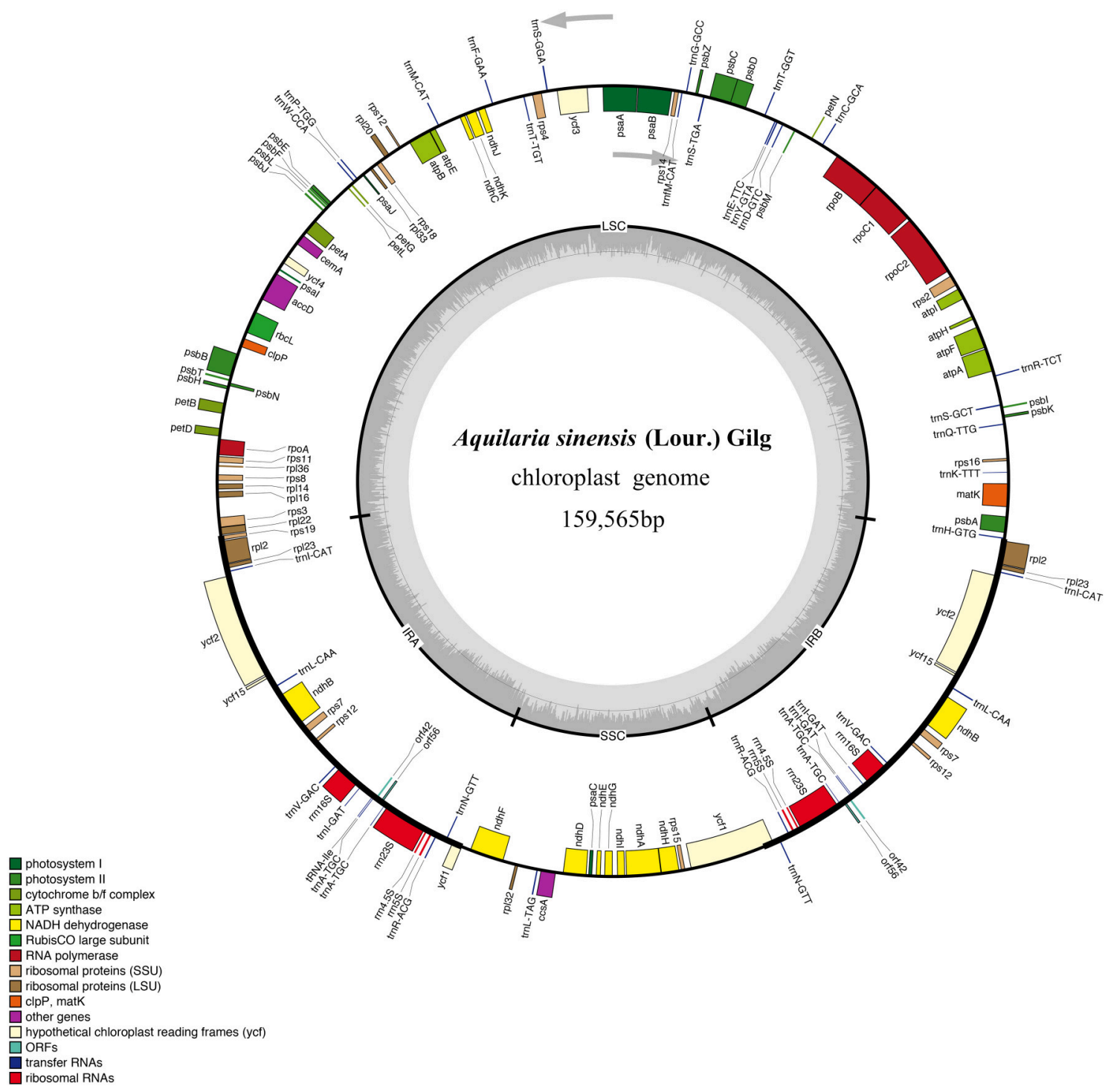

FIGURE 1 | Gene map of $\boldsymbol{A}$. sinensis chloroplast (cp) genome sequence. Organization of the $\mathrm{cp}$ genome of $A$. sinensis showing annotated genes. Genes drawn inside the circle are transcribed clockwise, and those outside are counter clockwise. Genes belonging to different functional groups are color-coded. The inner circle shows the locations of the large single-copy region, small single-copy, and the pair of inverted repeats (IRa and IRb). The darker gray in the inner circle corresponds to GC content, whereas the lighter gray corresponds to AT content. 
TABLE 1 | Gene contents in A. sinensis chloroplast genome.

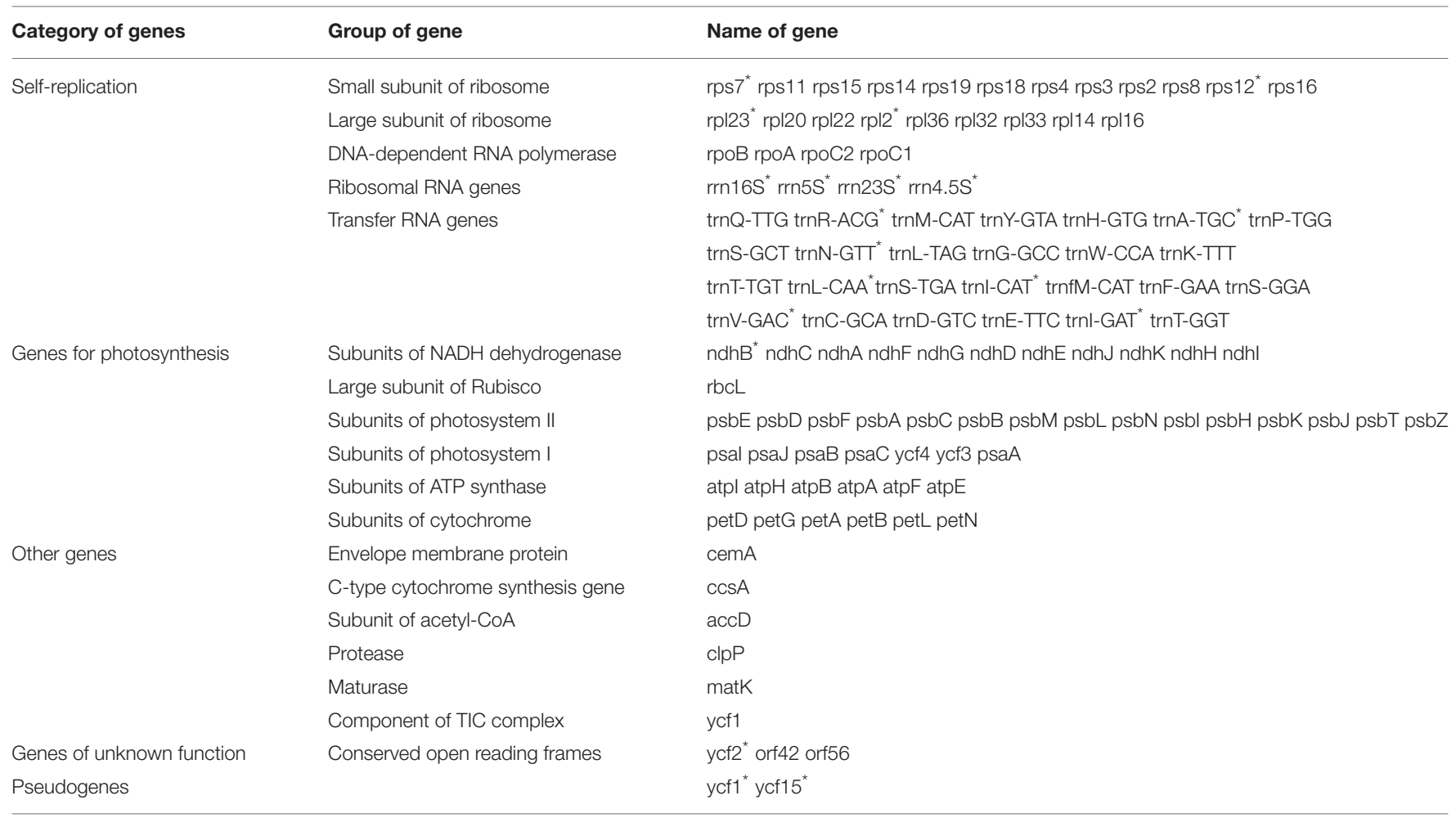

"Duplicated gene.

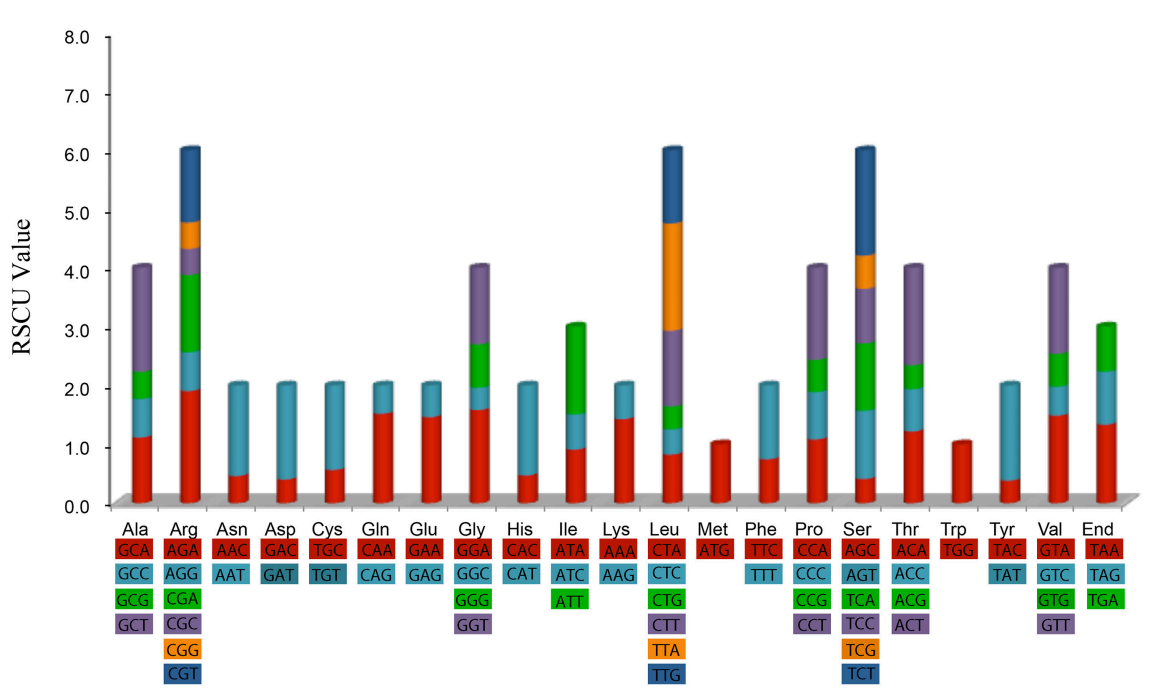

FIGURE 2 | Codon content of 20 amino acid and stop codon of $\mathbf{8 2}$ coding genes of Aquilaria sinensis chloroplast genome. Color of the histogram is corresponding to the color of codons.

87 potential protein-coding genes (Sato et al., 1999). The cp DNA from maize (Z. mays) consists of 140,387 bp with a total of 104 genes (Bedbrook and Bogorad, 1976). The complete cp DNA of Cedrus deodara is circular molecule of 119,298 bp with 114 genes (Ching et al., 2010). However, some parasitic plants, such as Conopholis americana, which demonstrate unique life cycles, are exceptions because the sizes of their cp genomes are beyond 115$165 \mathrm{~kb}$, with the smallest plastome of $45 \mathrm{~kb}$ in land plants (Wicke et al., 2013). The development of DNA sequencing technology has resulted in the extensive use of $\mathrm{cp}$ genomes for molecular marker and molecular phylogenetic studies (Tangphatsornruang et al., 2009; Takano and Okada, 2011; Awasthi et al., 2012; Jheng 


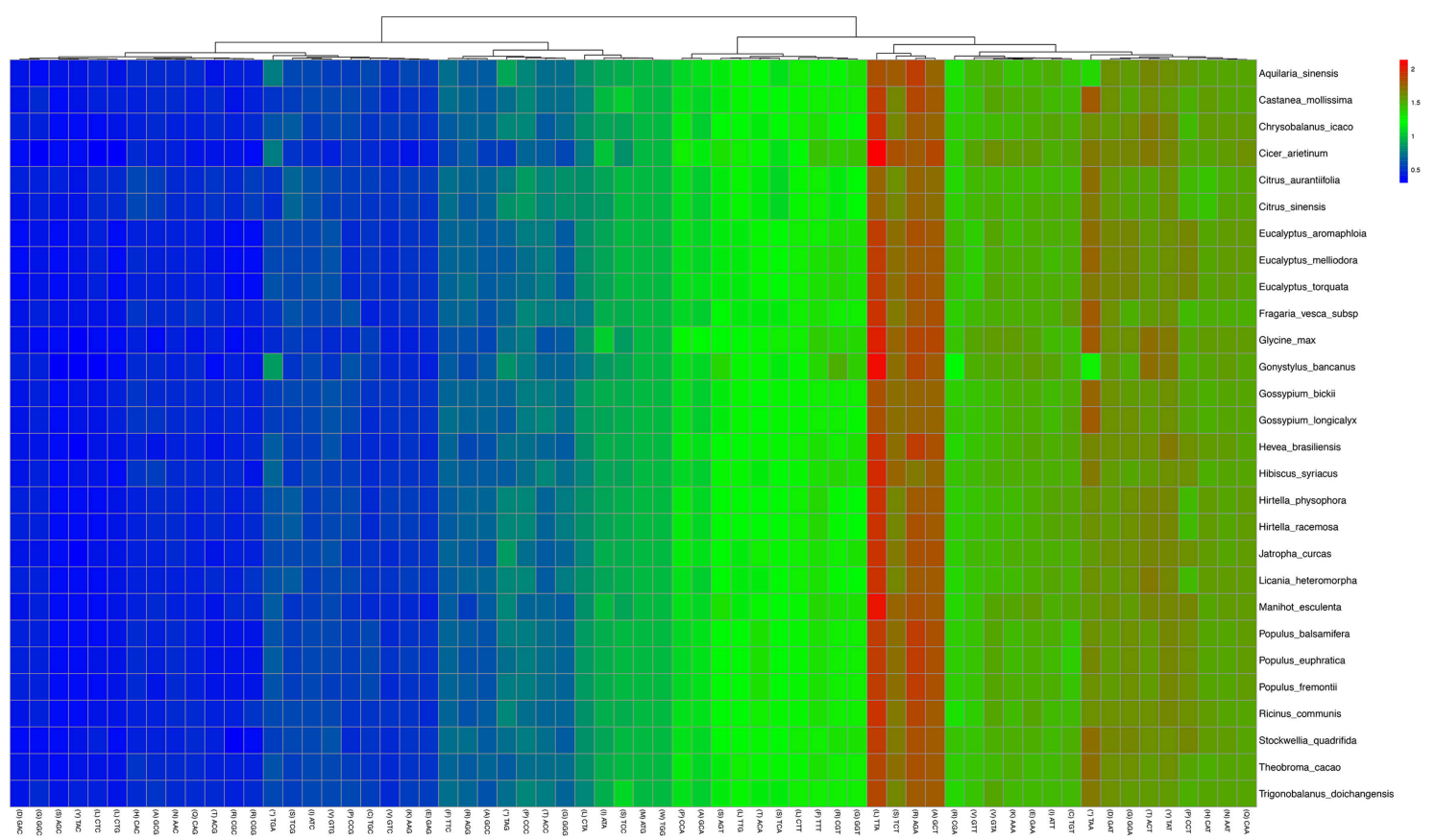

FIGURE 3 | Codon distribution of all merged protein-coding genes for all considered species. Color key: higher red values indicate higher RSCU value and lower blue values indicate lower RSCU value; A Hierarchical clustering (Lance and Williams, 1967; average linkage method) was performed for codon patterns (X-axis).

et al., 2012; Chen and Melis, 2013; Turner et al., 2013; Gaudeul et al., 2014).

Agarwood is widely used as a sedative, digestive, and antiemetic traditional drug. Agarwood sculpturing is valuable for interior decoration and is also popularly used as incense and perfume in Asia. The stems, branches, or roots of Aquilaria and Gyrinops trees are wounded and infected by fungi to produce agarwood (the wounds can be caused by wind, lightning strikes, gnawing of ants or insects, or microorganism invasion). Aquilaria sinensis is the only certified source for producing agarwood listed in China Pharmacopoeia (China pharmacopoeia Committee, 2010). All A. sinensis species are endangered because of the high demand for agarwood products; hence, these species are regulated under the Convention on International Trade in Endangered Species of Wild Fauna and Flora. However, the genomic resources for A. sinensis are limited, and little is known about the composition and organization of its $\mathrm{cp}$ genomes and their evolution. In this study, we report the complete cp genome sequence of A. sinensis (GenBank accession number: KT148967) in accordance with the Illumina Hiseq2500 standard protocol. Overall, the results provide basic genetic information on $A$. sinensis $\mathrm{cp}$ and the role of $A$. sinensis in plant systematics and evolution.

\section{MATERIALS AND METHODS \\ DNA Extraction and Sequencing}

Aquilaria sinensis fresh leaves were collected from a 2-yearold tree at the Experimental Farm of the Chinese Academy of
Tropical Agriculture Sciences, Hainan, PR China. The leaves were cleansed, frozen in liquid nitrogen, and ground using a tissue lyser. DNA was extracted using a Plant Genomic DNA Kit (Foregene Biotech, China). DNA was used to generate $500 \mathrm{bp}$ (insert size) paired-end library in accordance with the Illumina Hiseq2500 standard protocol. Approximately $3.1 \mathrm{~Gb}$ of raw data were generated with pair-end $125 \mathrm{bp}$ read length.

\section{De novo CP Genome Assembly}

The obtained nucleotide sequencing reads were qualitatively assessed and assembled to contigs by using SOAPdenovo2 (Luo et al., 2012) with kmer length of 83. The assembled contigs included a mixture of sequences from organellar and nuclear genomes. The average coverage of cp genomes is usually much higher than that of nuclear genomes because many cps are found in a single cell (Steele et al., 2012; Straub et al., 2012). Thus, a complete de novo assembly of the cp genomes was performed using the assembly quality-filtered reads that exhibit high coverage for the cp genomes. We sorted the assembled contigs by contig-read depth analysis of assemblies by using the high correlation between sequencing depth and number of copies in the genome. The quality-filtered reads were remapped to the assembled contigs to calculate the sequencing depth with BWA (Li and Durbin, 2009). Thus, the cp contigs with high coverage (more than $500 \times$ ) were isolated from the nuclear contigs by using the difference of read depths between contigs (Figure S1). All published cp genome sequences of dicotyledons were used as references to map the contigs with BLAST (Table S1) and thus confirm the cp genome contigs. Finally, all isolated $\mathrm{cp}$ contigs were combined, and reads 


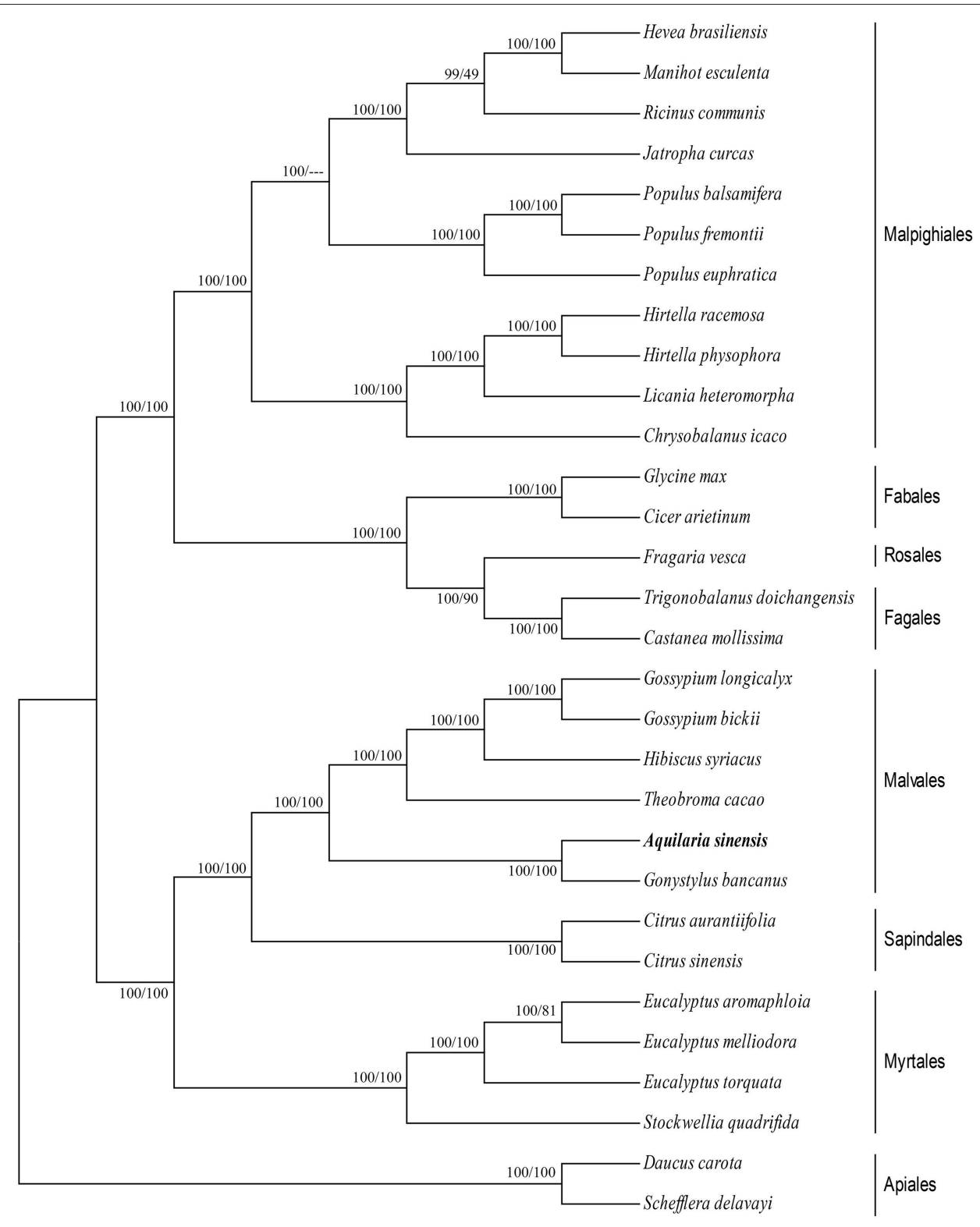

FIGURE 4 | Phylogenetic position of A.sinensis inferred by Maximum likelihood (ML) and Bayesian inference (BI) nucleic acid analyses of 82 protein-coding genes. The first number above the lines indicates the BI bootstrap value of the nucleic acid analysis for each clade, whereas the second number indicates the ML bootstrap value. The position of $A$. sinensisis shown in boldface.

were recaptured to isolate more $\mathrm{cp}$ DNA reads. Contigs were reassembled and extended to obtain a complete cp genome sequence.

\section{Genomic Annotation and Analysis}

Preliminarily gene annotation was performed using the online program Dual Organellar Genome Annotator (OGDRAW v1.2; Wyman et al., 2004) and cp Genome Annotation, Visualization, Analysis, and GenBank Submission Tool (Cheng et al., 2013) with plastid/bacterial genetic code and default conditions. Putative gene and protein sequences were BLAST-searched in non-redundant nucleotide database and non-redundant protein database to verify the exact gene and exon boundaries. All tRNA genes were further confirmed through online Trnascan-SE and tRNADB-CE search server (Griffiths-Jones et al., 2003; Schattner et al., 2005; Abe et al., 2011). The graphical map of the circular plastome was drawn using Organellar Genome DRAW (Lohse et al., 2007).

\section{Identification of Simple-Sequence Repeats (SSRs)}

The genomic sequence was applied to exploit potential SSRs by using MISA software (http://pgrc.ipk-gatersleben.de/ misa/). Tandem repeats of 1-6 nucleotides were considered as 


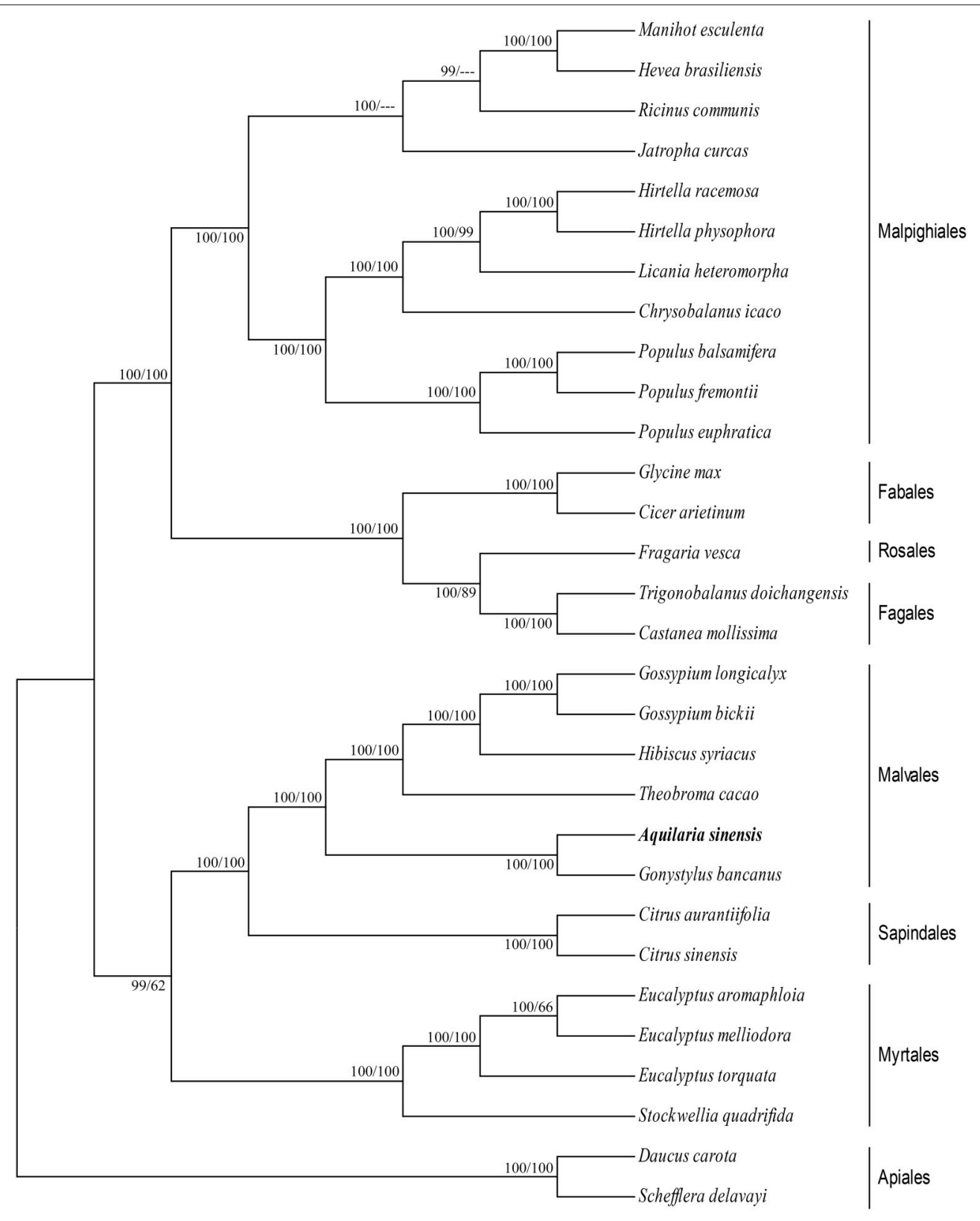

FIGURE 5 | Phylogenetic position of $\boldsymbol{A}$.sinensis inferred by $\mathbf{M L}$ and $\mathbf{B I}$ protein analyses of $\mathbf{8 2}$ protein-coding genes. The first number above the lines indicates the $\mathrm{Bl}$ bootstrap value of the protein analysis for each clade, whereas the second number indicates the ML bootstrap value. The position of $A$. sinensis is shown in boldface.

microsatellites. The minimum numbers of repeats were set to $10,6,5,5,5$, and 5 for mono-, di-, tri-, tetra-, penta-, and hexa-nucleotides, respectively.

\section{Long Repeat Analysis}

Web-based REPuter (http://bibiserv.techfak.uni-bielefeld.de/ reputer/) was used to analyze the repeat sequences, which included forward, reverse, and tandem repeats with minimal lengths of $30 \mathrm{bp}$ and edit distances of less than $3 \mathrm{bp}$.

\section{Codon Usage}

Codon usage was determined for all protein-coding genes. Statistical analyses of the distributions and visualization of codon usage in the form of heatmaps of 28 species of Angiosperms and histogram were conducted using $\mathrm{R}$ language with relative synonymous codon usage (RSCU) value (Sharp and Li, 1987).

RSCU is a simple measure of non-uniform usage of synonymous codons in a coding sequence. The RSCU value is the number of times a particular codon is observed, relative to the number of times that the codon would be observed for a 
TABLE 2 | Simple sequence repeats in $A$. sinensis chloroplast genome.

\begin{tabular}{|c|c|c|c|c|c|c|}
\hline $\begin{array}{l}\text { cpSSR } \\
\text { ID }\end{array}$ & $\begin{array}{c}\text { Repeat } \\
\text { motif }\end{array}$ & $\begin{array}{l}\text { Length } \\
\text { (bp) }\end{array}$ & Start & End & Region & Annotation \\
\hline 1 & (A) 10 & 10 & 1883 & 1892 & LSC & \\
\hline 2 & (T) 10 & 10 & 2023 & 2032 & LSC & \\
\hline 3 & (A) 12 & 12 & 4127 & 4138 & LSC & \\
\hline 4 & (A) 12 & 12 & 4803 & 4814 & LSC & \\
\hline 5 & (C) 10 & 10 & 5260 & 5269 & LSC & \\
\hline 6 & (A) 10 & 10 & 6662 & 6671 & LSC & \\
\hline 7 & (A) 15 & 15 & 7644 & 7658 & LSC & \\
\hline 8 & (A) 11 & 11 & 8033 & 8043 & LSC & \\
\hline 9 & (T) 11 & 11 & 8380 & 8390 & LSC & \\
\hline 10 & (T)11 & 11 & 9080 & 9090 & LSC & \\
\hline 11 & (T) 10 & 10 & 9863 & 9872 & LSC & \\
\hline 12 & $(T A) 6$ & 12 & 10743 & 10754 & LSC & \\
\hline 13 & (A) 10 & 10 & 13927 & 13936 & LSC & \\
\hline 14 & (T)10 & 10 & 14100 & 14109 & LSC & \\
\hline 15 & (TC)7 & 14 & 17620 & 17633 & LSC & \\
\hline 16 & (T)11 & 11 & 18009 & 18019 & LSC & rpoC2 \\
\hline 17 & (T) 10 & 10 & 19917 & 19926 & LSC & rpoC2 \\
\hline 18 & (T) 10 & 10 & 27649 & 27658 & LSC & rров \\
\hline 19 & (T) 10 & 10 & 30717 & 30726 & LSC & \\
\hline 20 & (A) 10 & 10 & 32194 & 32203 & LSC & \\
\hline 21 & (T) 10 & 10 & 44610 & 44619 & LSC & \\
\hline 22 & (A) 10 & 10 & 45233 & 45242 & LSC & \\
\hline 23 & (A) 10 & 10 & 47349 & 47358 & LSC & \\
\hline 24 & (A) 11 & 11 & 47627 & 47637 & LSC & \\
\hline 25 & (T) 10 & 10 & 48204 & 48213 & LSC & \\
\hline 26 & (T) 12 & 12 & 51015 & 51026 & LSC & \\
\hline 27 & (T)11 & 11 & 51316 & 51326 & LSC & \\
\hline 28 & (T) 10 & 10 & 51846 & 51855 & LSC & \\
\hline 29 & (A) 11 & 11 & 61867 & 61877 & LSC & \\
\hline 30 & (T) 11 & 11 & 62016 & 62026 & LSC & \\
\hline 31 & (A) 11 & 11 & 62578 & 62588 & LSC & \\
\hline 32 & $(T A) 6$ & 12 & 62964 & 62975 & LSC & \\
\hline 33 & (T) 10 & 10 & 64002 & 64011 & LSC & psbF \\
\hline 34 & (C) 10 & 10 & 66343 & 66352 & LSC & \\
\hline 35 & (T) 12 & 12 & 67133 & 67144 & LSC & cemA \\
\hline 36 & (T)11 & 11 & 71791 & 71801 & LSC & \\
\hline 37 & $(T A) 6$ & 12 & 77233 & 77244 & LSC & $\mathrm{psbN}$ \\
\hline 38 & (T)15 & 15 & 87280 & 87294 & LSC & rps19 \\
\hline 39 & (TA)7 & 14 & 113802 & 113815 & SSC & \\
\hline 40 & (A) 10 & 10 & 116349 & 116358 & SSC & \\
\hline 41 & (A) 10 & 10 & 116494 & 116503 & SSC & \\
\hline 42 & (T) 10 & 10 & 117050 & 117059 & SSC & \\
\hline 43 & (AT)7 & 14 & 117644 & 117657 & SSC & \\
\hline 44 & (T) 10 & 10 & 129560 & 129569 & SSC & $y c f 1^{*}$ \\
\hline 45 & (T) 13 & 13 & 132293 & 132305 & SSC & ycf1 \\
\hline
\end{tabular}

*Duplicated gene.

uniform synonymous codon usage (i.e., all codons for a given amino acid exhibit similar probabilities). The RSCU value in the absence of any codon usage bias is 1.00 , which is the case for the CDS sequence in the following example. A codon used less frequently than expected will achieve RSCU of $<1.00$, whereas codons used more frequently than expected may reach RSCU of $>1.00$.

\section{Phylogenetic Analysis}

The jModeltest 0.1.1 software was employed to analyze the general GTR+G+I model for nucleotide sequence and $\mathrm{HIVb}+\mathrm{I}+\mathrm{G}$ model for protein sequence by using optimized parameters (Posada, 2008). Phylogenetic analysis was subsequently performed using Maximum likelihood (ML) and Bayesian inference (BI) methods. ML analysis was conducted using RAxML8.1.5 with 1000 bootstrap replicates (Stamatakis, 2014). BI analysis was conducted using Phylobayes $4.1 \mathrm{~b}$ with two chain max diff $<0.01$ (Lartillot et al., 2009).

\section{CGView Comparison Tool (CCT) Map}

The A. sinensis cp genome was compared with other available cp genomes of Malvales by using CCT (Grant and Stothard, 2008). Genes were signed by Clusters of Orthologous Groups, and BLAST was used to align other genomes to A. sinensis. The results are shown as a circular map. AT distributions were measured on the basis of AT skewed using the equation: AT-skew $=(\mathrm{A}-\mathrm{T}) /(\mathrm{A}+\mathrm{T})$.

\section{RESULTS AND DISCUSSION}

\section{Genome Sequencing and Assembly}

A total of $2.48 \times 10^{7}$ reads with an average read length of 125 bp were obtained after low-quality bases and adapter sequences were trimmed. De novo assembly produced 691,722 contigs (2.78\%). The size of the A. sinensis cp genome was $159,565 \mathrm{bp}$ (Figure 1). The genome included an LSC region of $87,482 \mathrm{bp}$, an SSC region of 19,857 bp, and a pair of IRs (IRa and IRb) of 26,113 bp each (Table 1). The GC content was $37.11 \%$ (Table S2). However, the GC content was unevenly distributed in the entire cp genome, with the highest value in the IR regions $(42.86 \%)$, followed by the LSC (34.95\%) and SSC (31.58\%) regions. The frequency of codon usage was deduced for the $\mathrm{cp}$ genome on the basis of the CDS sequences. Notably, the AT contents were $54.64,62.31$, and $69.34 \%$ at the first, second, and third codon positions, respectively, within the protein-coding regions (Table S2). Bias toward higher AT content at the third codon position was consistent with the enrichment of $\mathrm{A}$ and $\mathrm{T}$, which has been widely observed in many other sequenced land plant cp genomes (Morton, 1998; Tangphatsornruang et al., 2009; Nie et al., 2012; Qian et al., 2013). The sequences of the A. sinensis cp genome were deposited in GenBank with accession number KT148967.

\section{Genomic Annotation}

The draft genome was drawn using OGDRAW v1.2 (Figure 1). The single collapsed IR contig was separated into two repeat regions. Assembly of the two IRs and LSC and SSC contigs covered the complete sequence without gaps. The positions of all genes identified in the cp genome and functional categorization of these genes are presented in Figure 1. The A. sinensis 
TABLE 3 | Long repeat sequences in A. sinensis chloroplast genome.

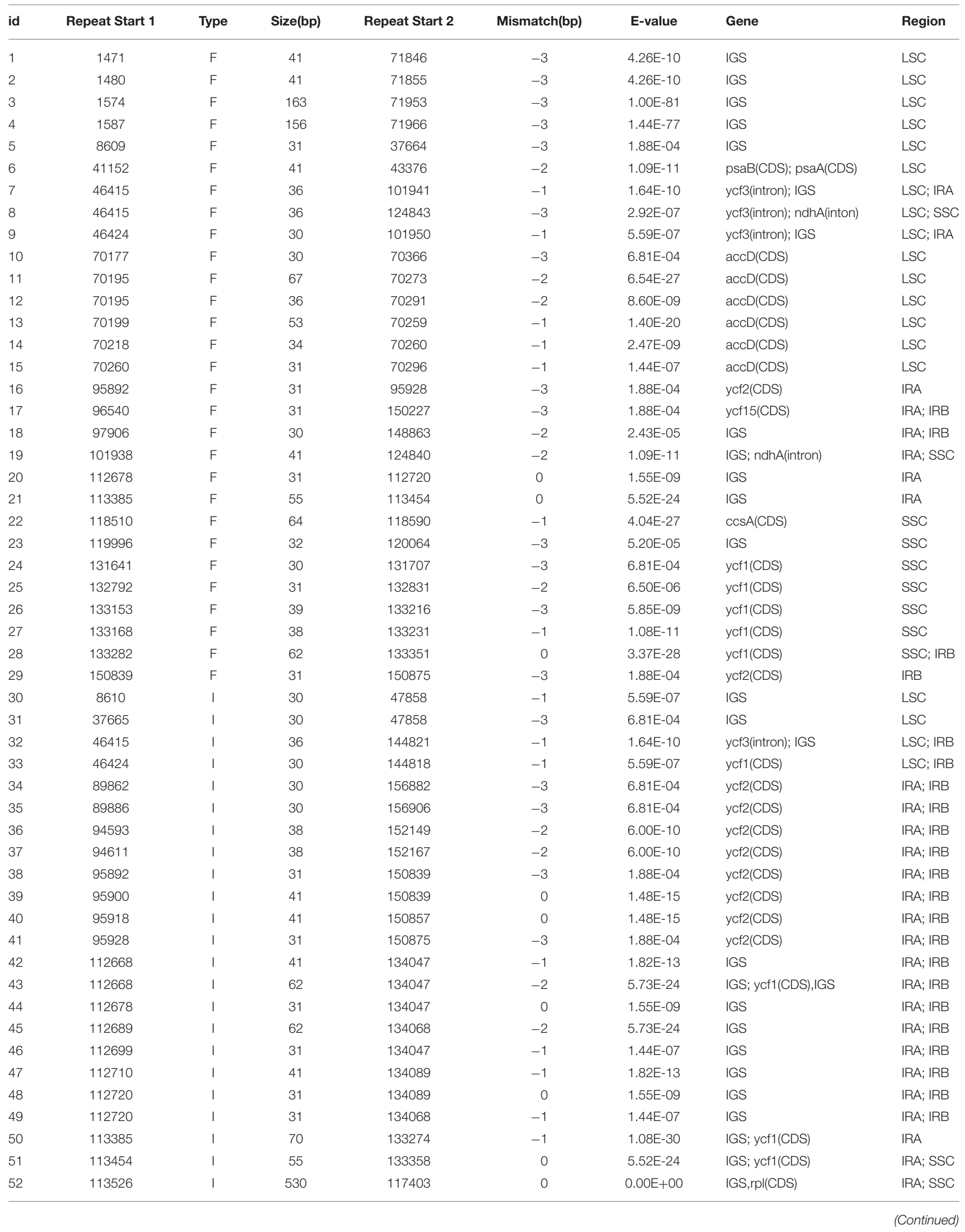




\begin{tabular}{|c|c|c|c|c|c|c|c|c|}
\hline id & Repeat Start 1 & Type & Size(bp) & Repeat Start 2 & Mismatch(bp) & E-value & Gene & Region \\
\hline 53 & 124840 & 1 & 41 & 144819 & -2 & $1.09 \mathrm{E}-11$ & ndhA(CDS, intron); IGS & SSC; IRB \\
\hline 54 & 59836 & $\mathrm{~T}$ & 31 & 59866 & 0 & 1.55E-09 & rps18 & LSC \\
\hline 55 & 112668 & $\mathrm{~T}$ & 41 & 112710 & -1 & $1.82 \mathrm{E}-13$ & IGS & IRA \\
\hline 56 & 118496 & $\mathrm{~T}$ & 78 & 118576 & -3 & $1.61 \mathrm{E}-31$ & IGS & SSC \\
\hline 57 & 132782 & $\mathrm{~T}$ & 41 & 132821 & -3 & $4.26 \mathrm{E}-10$ & $\operatorname{ycf1}(C D S)$ & SSC \\
\hline 58 & 133193 & $\mathrm{~T}$ & 44 & 133235 & 0 & $2.31 \mathrm{E}-17$ & ycf1(CDS) & SSC \\
\hline 59 & 133274 & $\mathrm{~T}$ & 70 & 133343 & -1 & $1.08 \mathrm{E}-30$ & $\operatorname{ycf1}(C D S)$ & SSC; IRB \\
\hline 60 & 134047 & $\mathrm{~T}$ & 41 & 134089 & -1 & $1.82 \mathrm{E}-13$ & IGS & $\mathrm{IRB}$ \\
\hline
\end{tabular}

F, Forward; I, Inverted; T, Tandem; IGS, intergenic space.

cp genome was 159,565 bp long with a typical quadripartite structure. A total of 113 functional genes were identified, which comprised 82 protein-coding genes, 27 tRNA genes, and 4 rRNA genes (Table 1). Comparing to the genes in other species (Figure S2), little change was found in gene structure. The very low level of recombination was also reported in the $\mathrm{cp}$ genome of land plant (Provan et al., 2001; Ravi et al., 2008). Among the 82 protein-coding genes, 75 were single-copy genes, and 7 were duplicates. Among the 31 RNA genes, 20 were unique, and 11 were duplicates. Among the 113 unique genes, 9 genes contained 1 intron (7 protein-coding and 2 tRNA genes), and 1 gene $(y c f 3)$ contained 2 introns (Table S3). The $y c f 3$ gene was similar to those in Globe artichoke and Metasequoia glyptostroboides (Chen et al., 2015; Curci et al., 2015). Out of the 10 genes with introns, 3 protein-coding genes were located in the LSC, 1 in the SSC, and 6 (4 protein-coding genes and 2 tRNAs) in the IR region. The $n d h A$ gene presented the largest intron (1148 bp). In addition, $n d h B$ and $r p l 2$ were identified as duplicate genes.

\section{SSR Analysis}

SSRs consist of 1-6 nucleotide repeat units, which are also known as microsatellites and short tandem repeats (Chen et al., 2006). SSRs are important in plant typing (Yang et al., 2011; Xue et al., 2012) and widely used for genetic molecular markers in population genetics (Doorduin et al., 2011; He et al., 2012). A total of 45 SSR regions were identified using the microsatellite identification tool (MISA) in A. sinensis cp genome (Table 2), accounting for $499 \mathrm{bp}$ of the total sequence $(0.3 \%)$, and 37 SSRs were only composed of A or T bases. Two SSRs were composed of $\mathrm{C}$ bases, and six SSRs were composed of dinucleotide (AT/TA/TC) repeats. Therefore, SSRs in A. sinensis cp genome were rich in $\mathrm{AT}$. $\operatorname{Poly}(\mathrm{A}) /(\mathrm{T})$ had been reported to exhibit higher proportion relative to $\operatorname{poly}(\mathrm{G}) /(\mathrm{C})$ in many plant families (Kumar et al., 2009; Melotto-Passarin et al., 2011; Nie et al., 2012; Martin et al., 2013). Among these SSRs, 36 SSRs were located in noncoding sections of the LSC/SSC region, and 9 SSRs in proteincoding genes ( $r p o C 2, r p o B, p s b F, c e m A, p s b N, r p s 19$, and $y c f 1)$. No tri- or tetra-nucleotide repeats over 15 bp long were found. The SSRs identified in this study may provide a new perspective to refine the phylogeny and elucidate the origin of cultivars.

\section{Large Repeat Analysis}

Large repeat sequences showed repeats with length of $\geq 30$ bp each. Sixty pairs of large repeat sequences with sequence identity of $>90 \%$ were found in the A. sinensis cp genomes (Table 3 ). The repeats ranged from 30 to $600 \mathrm{bp}$ in length and were repeated twice. A total of 33 large repeat sequences were located in protein-coding genes (e.g., $y c f 1$ and $y c f 2$ ), and 27 large repeat sequences were located in the intergenic regions. Numerous repeated sequences were identified in cp genomes, particularly in the intergenic spacer regions, and have been reported in several angiosperm lineages (Yang et al., 2013).

\section{Codon Usage}

Most protein-coding genes in these basal eudicots employ the standard ATG as the initiator codon. However, ATA, ATC, TTG, and ATT are also used as alternatives to ATG as the start codon. Among the $A$. sinensis cp protein-coding genes, nine genes were used alternatively to ATG as the start codon as follows: ATA for $a t p F$; ATT for $y c f 1$ and $p e t B$; ATC for $r p l 16$; GTG for $r p s 8, p s b C$, and $n d h D$; and TTG for $n d h A$ and rpoC1. In the N. tabacum cp genome, GTG was used as start codon for $r p s 19$, psbC, and $y c f 15$, whereas ACG was used for $p s b L$ and $n d h D$ (Sugiura et al., 1998). ACG and GTG were used as start codon for rpl2 and rps19, as reported in Oryza sativa (Liu and Xue, 2004).

Furthermore, the codon usage patterns of the 82 distinct cp protein-coding genes in A. sinensis were examined. All the protein-coding genes were composed of 26,160 codons. Interestingly, as synonymous codons, almost each of these codons contained half synonymous codon, which ended with A or T with high RSCU values, and the other half ended with $\mathrm{C}$ or $\mathrm{G}$ with low RSCU values (Table S4). These codon usage patterns may be driven by the composition bias of the high proportion of $\mathrm{A} / \mathrm{T}$ similar to those of other reported cp genomes (Raubeson et al., 2007; Delannoy et al., 2011) and mitochondrial genomes (Barth and Berendonk, 2011).

Figure 2 shows that the RSCU value increased with the number of codons that code a particular amino acid. The high RSCU value was probably attributed to the function of the amino acid or the structure of the peptide to avoid error in transcription.

Statistical analyses of the distributions and visualization of codon usage in the form of heatmaps of 28 species of Angiosperms (Figure 3) showed that approximately half of the codons were 


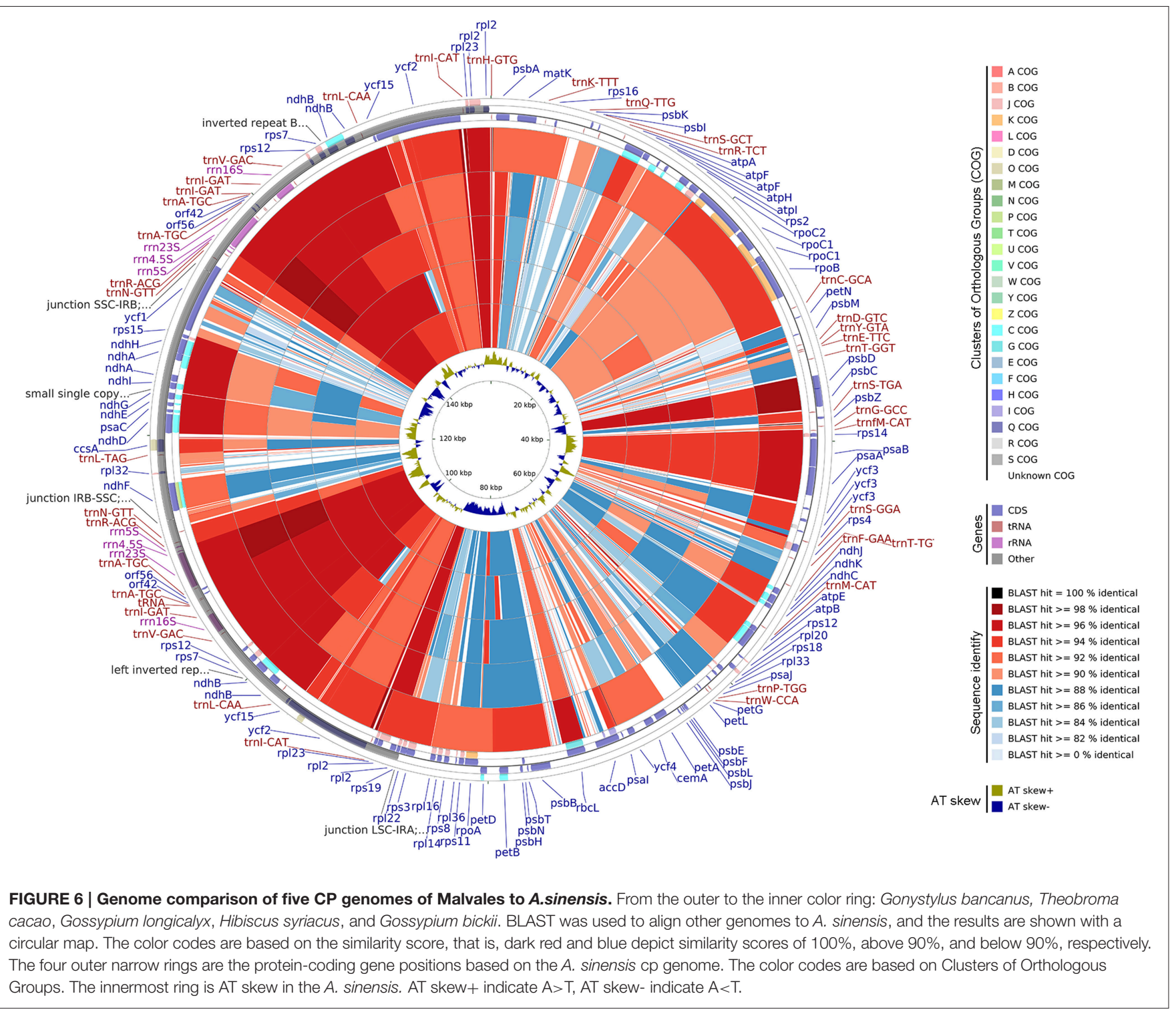

not frequently used. These codons were denoted in blue, which indicated RSCU value of $<1$ and weak codon bias. Almost twothirds of all the codons with high RSCU values ended with purine (A/T). Thus, we hypothesized that the codon in A. sinensis cp genome bias ended with $\mathrm{A} / \mathrm{T}$. This phenomenon was also found in many other plant and algal lineages (Morton, 1998). The distribution of codon usage in A. sinensis cp genome was most similar to the codon usage in Gonystylus bancanus cp genome.

\section{Phylogenetic Analyses}

cp genomes are significant in the research of phylogenetics, evolution, and molecular systematics. Numerous analytical studies have been conducted in the past decade to address phylogenetic issues at deep nodes by comparing multiple proteincoding genes (Lemieux et al., 2000; Delas Rivas et al., 2002; Moore et al., 2010) and complete sequences in cp genomes (Goremykin et al., 2004; Moore et al., 2007). These studies enhanced the understanding about enigmatic evolutionary relationships among Angiosperms. We examined the phylogenetic position of A. sinensis and relationships within Angiosperms. We previously selected 82 protein-coding genes commonly present in $\mathrm{cp}$ genomes of 29 species, including the $A$. sinensis cp genome sequenced in the current study. ML and BI nucleic acid analyses were performed, and the results are summarized in Figures 4, 5. Similar phylogenetic topologies were found in the ML and BI nucleic acid analyses. Bootstrap values were very high, and 28 of 29 nodes with $100 \%$ bootstrap values were found using ML. Up to 25 out of the 29 nodes with bootstrap values of $\geq 99 \%$ were found using BI. A. sinensis and G. bancanus were grouped in Malvales, with $100 \%$ bootstrap values in the ML and BI phylogenetic trees. Similarly, in the ML protein analyses, 27 of the 29 nodes yielded bootstrap values of $100 \%$, and 24 nodes reached $\geq 99 \%$ in the BI. ML and BI protein analyses showed that $A$. sinensis can also be grouped with G. bancanus within Malvales. The phylogenetic 
results strongly support the position of A.sinensis within the Malvales order. However, the results were inconsistent because A.sinensis was classified into Myrtales according to the traditional morphological classification of China.

\section{CCT Map}

Five available cp genomes of Malvales were compared with the A.sinensis cp genome by using CCT (Figure 6). The sequence identity between the A.sinensis cp and other representatives of the Malvales was analyzed. The results showed that G. bancanus cp genome achieved the highest sequence similarity (>90\%), which was consistent with the result of the phylogenetic analysis. The highest similar region across all five $\mathrm{cp}$ genomes occurred in the IR region. LSC and SSC regions were less conservative; thus, many regions with identity results were lower than $90 \%$, such as the $y c f 1$ gene in the SSC region and intergenic space regions. This evolutionary conserved feature was reported in the IR region in cp (Curtis and Clegg, 1984; Palmer, 1985).

\section{CONCLUSIONS}

The complete cp sequence of traditional medicinal plant $A$. sinensis was assembled, annotated, and analyzed. The cp genome consisted of one LSC, one SSC, and two IR regions. A total of 45 polymorphic SSR loci and 60 pairs of large repeats were identified in the $A$. sinensis cp genome. These repeat motifs can be selected to develop markers and conduct phylogenetic analysis. Both ML and BI phylogenetic analyses strongly supported the position of $A$. sinensis as a sister to $G$. bancanus within the Malvales order. The distribution of codon usage in A. sinensis cp genome was most similar to that in $G$. bancanus cp genome. CCT analytical results also indicated that the $A$. sinensis cp genome achieved higher sequence similarity than the G. bancanus cp genome. However, the traditional morphological classification of China classified A. sinensis into Myrtales. The data obtained in this study will be beneficial for further investigations on $A$.

\section{REFERENCES}

Abe, T., Ikemura, T., Sugahara, J., Kanai, A., Ohara, Y., Uehara, H., et al. (2011). tRNADB-CE 2011: tRNA gene database curated manually by experts. Nucleic Acids Res. 39, 210-213. doi: 10.1093/nar/gkq1007

Awasthi, P., Ahmad, I., Gandhi, S. G., and Bedi, Y. S. (2012). Development of chloroplast microsatellite markers for phylogenetic analysis in Brassicaceae. Acta Biol. Hung. 63, 463-473. doi: 10.1556/ABiol.63.2012.4.5

Barth, D., and Berendonk, T. U. (2011). The mitochondrial genome sequence of the ciliate Paramecium caudatum reveals a shift in nucleotide composition and codon usage within the genus Paramecium. BMC Genomics 12:272. doi: 10.1186/1471-2164-12-272

Bedbrook, J. R., and Bogorad, L. (1976). Endonuclease recognition sites mapped on Zea mays chloroplast DNA. Proc. Natl. Acad. Sci. U.S.A. 73, 4309-4313. doi: 10.1073/pnas.73.12.4309

Chen, C., Zhou, P., Choi, Y. A., Huang, S., and Gmitter, F. G. Jr. (2006). Mining and characterizing microsatellites from citrus ESTs. Theor. Appl. Genet. 112, 1248-1257. doi: 10.1007/s00122-006-0226-1 doi: 10.1007/s00122-006-0226-1

Chen, H., and Melis, A. (2013). Marker-free genetic engineering of the chloroplast in the green microalga Chlamydomonas reinhardtii. Plant Biotechnol. J. 11, 818-828. doi: 10.1111/pbi.12073 sinensis. Moreover, the results will help expand the understanding about the evolutionary history of the Malvales order, particularly regarding the role of $A$. sinensis in plant systematics and evolution.

\section{AUTHOR CONTRIBUTIONS}

YW designed and performed the experiment as well as drafted the manuscript. XC and SP conceived the study and revised the manuscript. DZ, XJ, WM, and HD prepared the samples and analyzed part of the data. All the authors have read and approved the final manuscript.

\section{ACKNOWLEDGMENTS}

This research was supported by the Natural Science Foundation of Hainan of China (No. 314115) and the National Nonprofit Institute Research Grant of CATAS-ITBB (ITBB140201 and ITBB2015ZD05).

\section{SUPPLEMENTARY MATERIAL}

The Supplementary Material for this article can be found online at: http://journal.frontiersin.org/article/10.3389/fpls.2016. 00280

\section{Figure $\mathrm{S} 1$ | Coverage depth of contigs of $A$. sinensis CP genome.}

Figure S2 | Comparisons of CP genomic structure among five land plants, including $\boldsymbol{A}$. sinensis, using Easyfig. The arrowheads indicate genes with their orientations and positions. The orange arrows indicate the coding regions of genes. Gray ligature indicate positions and similarity of the genes of five land plants.

\section{Table S1 | List of CP genomes used as reference to map to contigs.}

Table S2 | Summary of $A$. sinensis chloroplast genome characteristics.

Table S3 | The genes in the A. sinensis chloroplast genome with introns.

Table S4 | Relative synonymous codon usage (RSCU) for the A. sinensis chloroplast genome.

Chen, J. H., Hao, Z. D., Xu, H. B., Yang, L. M., Liu, G. X., Sheng, Y., et al. (2015). The complete chloroplast genome sequence of the relict woody plant Metasequoia glyptostroboides Huet Cheng. Front. Plant. Sci. 6:447. doi: $10.3389 /$ fpls.2015.00447

Cheng, J., Zeng, X., Ren, G., and Liu, Z. (2013). CGAP: a new comprehensive platform for the comparative analysis of chloroplast genomes. BMC Bioinformatics 14:95. doi: 10.1186/1471-2105-14-95

China pharmacopoeia Committee (2010). The Pharmacopoeia of People's Republic of China. Beijing:Chemical Industry Press.

Ching, P. L., Jen, P. H., Chung, S., Wu, Chih, Y. H., and Shu, M. C. (2010). Comparative chloroplast genomics reveals the evolution of Pinaceae Genera and subfamilies. Genome Biol. Evol. 2, 504-517. doi: 10.1093/gbe/evq036

Corriveau, J. L., and Coleman, A. W. (1988). Rapid screening method to detect potential biparental inheritance of plastid DNA and results for over 200 angiosperm species. Am. J. Bot. 75, 1443-1458. doi: 10.2307/2444695

Curci, P. L., De Paola, D., Danzi, D., Vendramin, G. G., and Sonnante, G. (2015). Complete Chloroplast genome of the multifunctional crop Globe Artichoke and comparison with other Asteraceae. PLoS ONE 10:e0120589. doi: 10.1371/journal.pone.0120589

Curtis, S. E., and Clegg, M. T. (1984). Molecular evolution of chloroplast DNA sequences. Mol. Biol. Evol. 1, 291-301. 
Delannoy, E., Fujii, S., Des Francs-Small, C. C., Brundrett, M., and Small, I. (2011). Rampant gene loss in the underground orchid Rhizanthella gardneri highlights evolutionary constraints on plastid genomes. Mol. Biol. Evol. 28, 2077-2086. doi: $10.1093 / \mathrm{molbev} / \mathrm{msr} 028$

Delas Rivas, J., Lozano, J. J., and Ortiz, A. R. (2002). Comparative analysis of chloroplast genomes: functional annotation, genome-based phylogeny, and deduced evolutionary patterns. Genome Res. 12, 567-583. doi: 10.1101/gr.209402

Doorduin, L., Gravendeel, B., Lammers, Y., Ariyurek, Y., Chin-A-Woeng, T., and Vrieling, K. (2011). The complete chloroplast genome of 17 individuals of pest species Jacobaeavulgaris: SNPs,microsatellites and barcoding markers for population and phylogenetic studies. DNA Res. 18, 93-105. doi: 10.1093/dnares/dsr002

Gaudeul, M., Gardner, M. F., Thomas, P., Ennos, R. A., and Hollingsworth, P. M. (2014). Evolutionary dynamics of emblematic Araucaria species (Araucariaceae) in New Caledonia: nuclear and chloroplast markers suggest recent diversification, introgression, and a tight link between genetics and geography within species. BMC Evol. Biol. 14:171. doi: 10.1186/s12862-0140171-6

Goremykin, V. V., Hirsch-Ernst, K. I., Wolfl, S., and Hellwig, F. H. (2004). The chloroplast genome of Nymphaea alba: whole-genome analyses and the problem of identifying the most basal angiosperm. Mol. Biol. Evol. 21, 1445-1454. doi: 10.1093/molbev/msh147

Grant, J. R., and Stothard, P. (2008). The CGView Server: a comparative genomics tool for circular genomes. Nucleic. Acids. Res. 36 (Web Server issue), W181-W184. doi: 10.1093/nar/gkn179

Griffiths-Jones, S., Bateman, A., Marshall, M., Khanna, A., and Eddy, S. R. (2003). Rfam: an RNA family database. Nucleic Acids Res. 31, 439-441. doi: 10.1093/nar/gkg006

He, S., Wang, Y., Volis, S., Li, D., and Yi, T. (2012). Genetic diversity and population structure: implications for conservation of wildsoybean (Glycinesoja Sieb.et Zucc)based on nuclear and chloroplast microsatellite variation. Int. J. Mol. Sci. 13, 12608-12628. doi: 10.3390/ijms131012608

Jheng, C., Chen, T., Lin, J., Chen, T., Wu, W., and Chang, C. (2012). The comparative chloroplast genomic analysis of photosynthetic orchids and developing DNA markers to distinguish Phalaenopsis orchids. Plant Sci. 190, 62-73. doi: 10.1016/j.plantsci.2012.04.001

Kumano, M. (1986). Clone bank of the tobacco (Nicotiana tabacum) chloroplast genome as a set of overlapping restriction endonuclease fragments: mapping of eleven ribosomal protein genes. Plant Sci. 44, 211-216. doi: 10.1016/01689452(86)90093-2

Kumar, S., Hahn, F. M., McMahan, C. M., Cornish, K., and Whalen, M. C. (2009). Comparative analysis of the complete sequence of the plastid genome of Parthenium argentatum and identification of DNA barcodes to differentiate Parthenium species and lines. BMC Plant Biol. 9:131. doi: 10.1186/1471-222 9-9-131

Lance, G. N., and Williams, W. T. (1967). A general theory of classificatory sorting strategies 1. hierarchical systems. Comput. J. 9, 373-380. doi: 10.1093/comjnl/9.4.373

Lartillot, N., Lepage, T., and Blanquart, S. (2009). PhyloBayes 3: a Bayesian software package for phylogenetic reconstruction and molecular dating. Bioinformatics. 25, 2286-2288. doi:10.1093/bioinformatics/btp368

Lemieux, C., Otis, C., and Turmel, M. (2000). Ancestral chloroplast genome in Mesostigma viride reveals an early branch of green plant evolution. Nature 403, 649-652. doi: 10.1038/35001059

Li, H., and Durbin, R. (2009). Fast and accurate short read alignment with Burrows-Wheeler transform. Bioinformatics 25, 1754-1760. doi: 10.1093/bioinformatics/btp324

Liu, Q. B., and Xue, Q. Z. (2004). Codon usage in the chloroplast genome of rice (Oryza sativa L. ssp. japonica). Acta Agron. Sin. 30, 1220-1224.

Lohse, M., Drechsel, O., and Bock, R. (2007). Organellar Genome DRAW (OGDRAW): a tool for the easy generation of high-quality custom graphical maps of plastid and mitochondrial genomes. Curr. Genet. 52, 267-274. doi: 10.1007/s00294-007-0161-y

Luo, R., Liu, B., Xie, Y., Li, Z., Huang, W., Yuan, J., et al. (2012). SOAPdenovo2: an empirically improved memory-efficient short-read de novo assembler. Gigascience 1:18. doi: 10.1186/2047-217x-1-18
Martin, G., Baurens, F. C., Cardi, C., Aury, J. M., and D'Hont, A. (2013). The complete chloroplast genome of banana (Musa acuminata, Zingiberales): insight into plastid monocotyledon evolution. PLOS ONE 8:e67350. doi: 10.1371/journal.pone.0067350

Melotto-Passarin, D. M., Tambarussi, E. V., Dressano, K., De Martin, V. F., and Carrer, H. (2011). Characterization of chloroplast DNA microsatellites from Saccharum spp and related species. Genet. Mol. Res. 10, 2024-2033. doi: 10.4238/vol10-3gmr1019

Moore, M. J., Bell, C. D., Soltis, P. S., and Soltis, D. E. (2007). Using plastid genome-scale data to resolve enigmatic relationships among basal angiosperms. Proc. Natl. Acad. Sci. U.S.A. 104, 19363-19368. doi: 10.1073/pnas.0708 072104

Moore, M. J., Soltis, P. S., Bell, C. D., Burleigh, J. G., and Soltis, D. E. (2010). Phylogenetic analysis of 83 plastid genes further resolves the early diversification of eudicots. Proc. Natl. Acad. Sci. U.S.A. 107, 4623-4628. doi: 10.1073/pnas.0907801107

Morton, B. R. (1998). Selection on the codon bias of chloroplast and cyanelle genes indifferent plant and algal lineages. J. Mol. Evol. 46, 449-459. doi: 10.1007/PL00006325

Neuhaus, H. E., and Emes, M. J. (2000). Nonphoto synthetic metabolism in plastids. Annu. Rev. Plant Physiol. Plant Mol. Biol. 51, 111-140. doi: 10.1146/annurev.arplant.51.1.111

Nie, X., Lv, S., Zhang, Y., Du, X., Wang, L., Biradar, S. S., et al. (2012). Complete chloroplast genome sequence of a major invasive species, crofton weed (Ageratinaadenophora). PLoS ONE 7:e36869. doi: 10.1371/journal.pone.0036869

Palmer, J. D. (1985). Comparative organization of chloroplast genomes. Annu. Rev. Genet. 19, 325-354. doi: 10.1146/annurev.ge.19.120185.001545

Palmer, J. D. (1991). "Plastid chromosomes: structure and evolution,” in Molecular Biology of Plastids, ed L. Bogorad (San Diego, CA: Academic Press), 5-53.

Posada, D. (2008). jModelTest: phylogenetic model averaging. Mol. Biol. Evol. 25, 1253-1256. doi:10.1093/molbev/msn083

Provan, J., Powell, W., and Hollingsworth, P. M. (2001). Chloroplast microsatellites: new tools for studies in plant ecology and evolution. Trends Ecol. Evol. 16, 142-147. doi: 10.1016/S0169-5347(00)02097-8

Qian, J., Song, J., Gao, H., Zhu, Y., Xu, J., Pang, X., et al. (2013). The complete chloroplast genome sequence of the medicinal plant Salvia miltiorrhiza. PLoS ONE 8:e57607. doi: 10.1371/journal.pone.0057607

Raubeson, L. A., and Jansen, R. K. (2005). "Chloroplast genomes of plants," in Plant Diversity and Evolution: Genotypic and Phenotypic Variation in Higher Plants, ed R. J. Henry (Cambridge, MA: CABI), 45-68.

Raubeson, L. A., Peery, R., Chumley, T. W., Dziubek, C., Fourcade, H. M., Boore, J. L., et al. (2007). Comparative chloroplast genomics: analyses including new sequences from the angiosperms Nuphar advena and Ranunculus macranthus. BMC Genomics 8:174. doi: 10.1186/1471-2164-8-174

Ravi, V., Khurana, J. P., Tyagi, A. K., and Khurana, P. (2008). An update on chloroplast genome. Plant Syst. Evol. 271, 101-122. doi: 10.1007/s00606-0070608-0

Sato, S., Nakamura, Y., Kaneko, T., Asamizu, E., and Tabata, S. (1999). Complete structure of the chloroplast genome of Arabidopsis thaliana. DNAquilaria Res. 6, 283-290. doi: 10.1093/dnares/6.5.283

Schattner, P., Brooks, A. N., and Lowe, T. M. (2005). The tRNAscan-SE, snoscan and snoGPS web servers for the detection of tRNAs and snoRNAs. Nucleic Acids Res. 33, W686-W689. doi: 10.1093/nar/gki366

Sharp, P. M., and Li, W. H. (1987). The codon adaptation index-a measure of directional synonymous codon usage bias, and its potential applications. Nucleic Acids Res. 15, 1281-1295. doi: 10.1093/nar/15.3.1281

Stamatakis, A. (2014). RAxML Version 8: a tool for phylogenetic analysis and post-analysis of large phylogenies. Bioinformatics 30, 1312-1313. doi: 10.1093/bioinformatics/btu033

Steele, P. R., Hertweck, K. L., Mayfield, D., McKain, M. R., Leebens-Mack, J., Pires, J. C., et al. (2012). Quality and quantity of data recovered from massively parallel sequencing: examples in asparagales and poaceae. Am. J. Bot. 99, 330-348. doi: 10.3732/ajb.1100491

Straub, S. C., Parks, M., Weitemier, K., Fishbein, M., Cronn, R. C., and Liston, A. (2012). Navigating the tip of the genomic iceberg: next-generation sequencing for plant systematics. Am. J. Bot. 99, 349-364. doi: 10.3732/ajb.1100335 
Sugiura, M., Hirose, T., and Sugita, M. (1998). Evolution and mechanism of translation in chloroplast. Annu. Rev. Genet. 32, 437-459. doi: 10.1146/annurev.genet.32.1.437

Takano, A., and Okada, H. (2011). Phylogenetic relationships among subgenera, species, and varieties of Japanese Salvia L. (Lamiaceae). J. Plant. Res. 124, 245-252. doi: 10.1007/s10265-010-0367-9

Tangphatsornruang, S., Sangsrakru, D., Chanprasert, J., Uthaipaisanwong, P., Yoocha, T., Jomchai, N., et al. (2009). The chloroplast genome sequence of mungbean (Vignaradiata) determined by high-throughput pyrosequencing: structural organization and phylogenetic relationships. DNAquilaria Res. 17, 1-22. doi: 10.1093/dnares/dsp025

Turner, B., Munzinger, J. E. R. O., Duangjai, S., Temsch, E. M., Stockenhuber, R., Barfuss, M. H., et al. (2013). Molecular phylogenetics of New Caledonian Diospyros (Ebenaceae) using plastid and nuclear markers. Mol. Phylogenet. Evol. 69, 740-763. doi: 10.1016/j.ympev.2013.07.002

Wicke, S., Muller, K. F., de Pamphilism, C. W., Quandt, D., Wickett, N. J., Zhang, Y., et al. (2013). Mechanisms of functional and physical genome reduction in photosynthetic and nonphotosynthetic parasitic plants of the broomrape family. Plant Cell. 25, 3711-3725. doi: 10.1105/tpc.113.113373

Wolfe, K. H., Li, W. H., and Sharp, P. M. (1987). Rates of nucleotide substitution vary greatly among plant mitochondrial, chloroplast, and nuclear DNAs. Proc. Natl. Acad. Sci. U.S.A. 84, 9054-9058. doi: 10.1073/pnas.84.24.9054

Wyman, S. K., Jansen, R. K., and Boore, J. L. (2004). Automatic annotation of organellar genomes with DOGMA. Bioinformatics 20, 3252-3255. doi: 10.1093/bioinformatics/bth352
Xue, J., Wang, S., and Zhou, S. L. (2012). Polymorphic chloroplast microsatellite loci in Nelumbo (Nelumbonaceae). Am. J. Bot. 99, e240-e244. doi: 10.3732/ajb.1100547

Yang, A. H., Zhang, J. J., Yao, X. H., and Huang, H. W. (2011). Chloroplast microsatellite markers in Liriodendron tulipifera (Magnoliaceae) and crossspecies amplification in L.chinense. Am. J. Bot. 98, e123-e126. doi 10.3732/ajb.1000532

Yang, J. B., Yang, S. X., Li, H. T., Yang, J., and Li, D. Z. (2013). Comparative chloroplast genomes of Camellia species. PLoS ONE 8:e73053. doi: 10.1371/journal.pone.0073053

Zhang, Q., Liu, Y., and Sodmergen (2003). Examination of the cytoplasmic DNA in male reproductive cells to determine the potential for cytoplasmic inheritance in 295 angiosperm species. Plant Cell Physiol. 44, 941-951. doi: $10.1093 / \mathrm{pcp} / \mathrm{pcg} 121$

Conflict of Interest Statement: The authors declare that the research was conducted in the absence of any commercial or financial relationships that could be construed as a potential conflict of interest.

Copyright (C) 2016 Wang, Zhan, Jia, Mei, Dai, Chen and Peng. This is an open-access article distributed under the terms of the Creative Commons Attribution License (CC $B Y)$. The use, distribution or reproduction in other forums is permitted, provided the original author(s) or licensor are credited and that the original publication in this journal is cited, in accordance with accepted academic practice. No use, distribution or reproduction is permitted which does not comply with these terms. 